\title{
Penentuan Cadangan Premi Asuransi Jiwa Seumur Hidup Menggunakan Metode Zillmer
}

\author{
Nur Iriana ${ }^{1}$, Ika Purnamasari $^{2}$, and Yuki Novia Nasution ${ }^{3}$
}

\begin{abstract}
Premium reserve is insurance company liability to pay some amount of fund that have to be prepared by the company on the later day. The premium reserve can be determined by using two methods, they are retrospective reserve and prospective reserve. This research used the simulation data of whole life insurance on the 25-35 years-old insured based on the gender and the cost which has been determined by PT. X Samarinda. Premium reserve will be calculated by using Zillmer method in prospective reserve. Based on analysis result, it is found that the Zillmer premium reserve characteristic of men insured is bigger than the Zillmer premium reserve of women. Zillmer premium reserve used Indonesia Mortality Tabel 1999 is higher than Indonesia Mortality Tabel 2011. Thus, the use Indonesia Mortality Tabel 1999 is more profitable for insurance company than Indonesia Mortality Tabel 2011.
\end{abstract}

Keywords: Premium Reserve, Prospective Reserve, Zillmer Method, Indonesia Mortality Tabel.

\begin{abstract}
Abstrak
Cadangan premi adalah kewajiban perusahaan asuransi untuk membayar sejumlah dana yang harus disiapkan oleh perusahaan asuransi di kemudian hari. Cadangan premi dapat ditentukan menggunakan dua metode, yaitu cadangan retrospektif dan cadangan prospektif. Dalam penelitian ini menggunakan data simulasi asuransi jiwa seumur hidup pada nasabah berusia 25-35 tahun berdasarkan jenis kelamin dan biaya yang telah ditentukan oleh PT. X Samarinda. Cadangan premi akan dihitung menggunakan metode Zillmer pada cadangan prospektif. Perhitungan cadangan premi dibantu dengan Tabel Mortalitas Indonesia 1999 dan Tabel Mortalitas Indonesia 2011. Berdasarkan hasil analisis diperoleh karakteristik cadangan premi Zillmer nasabah laki-laki lebih besar dibandingkan dengan cadangan premi Zillmer nasabah perempuan. Cadangan premi Zillmer menggunakan Tabel Mortalitas Indonesia 1999 lebih tinggi dibandingkan dengan Tabel Mortalitas Indonesia 2011. Dengan demikian, penggunaan Tabel Mortalitas Indonesia 1999 lebih menguntungkan perusahaan asuransi dibandingkan dengan Tabel Mortalitas Indonesia 2011.
\end{abstract}

Kata Kunci : Cadangan Premi, Cadangan Prospektif, Metode Zillmer, Tabel Mortalitas Indonesia.

\author{
${ }^{1}$ Jurusan Matematika, Fakultas MIPA, Universitas Mulawarman, Indonesia \\ email:nuririana_bl3@yahoo.com \\ ${ }^{2}$ Laboratorium Statistika Ekonomi dan Bisnis, Fakultas MIPA, Universitas Mulawarman, \\ Indonesia \\ email: ika.purnamasari@ymail.com \\ ${ }^{3}$ Laboratorium Matematika Komputasi, Fakultas MIPA, Universitas Mulawarman, Indonesia \\ email: yuki.novia.n@gmail.com
}




\section{Nur Iriana, Ika Purnamasari, and Yuki Novia Nasution}

\section{Pendahuluan}

Pada dasarnya, dalam kehidupan, manusia dapat menjamin keamanan dirinya serta keluarganya dari risiko-risiko yang membahayakan kesehatannya. Mulai dari risiko sakit, kecelakaan, kerugian, hingga risiko kematian yang selalu datang dan tidak dapat diprediksi kapan dan karena apa terjadi. Salah satu cara meminimalkan risiko adalah dengan mengikutsertakan diri dalam program asuransi. Asuransi jiwa adalah sebuah janji dari perusahaan asuransi (pihak penanggung) kepada nasabahnya (tertanggung) bahwa apabila nasabah mengalami risiko kematian dalam hidupnya, perusahaan asuransi akan memberikan santunan[1].

Asuransi jiwa dibagi menjadi empat jenis produk asuransi jiwa yaitu asuransi jiwa seumur hidup (Whole Life Insurance), asuransi jiwa berjangka (Term Life Insurance), dan asuransi jiwa dwiguna (Endoment). Asuransi Jiwa seumur hidup adalah jenis dasar asuransi jiwa yang memberi proteksi asuransi seumur hidup.

Premi adalah sejumlah uang yang dibayarkan oleh tertanggung kepada penanggung yang besarnya sudah ditentukan. Premi yang dibayarkan oleh pemegang polis (tertanggung) akan dialokasikan oleh perusahaan asuransi untuk santunan atau manfaat yang akan dikembalikan ke tertanggung, operasional perusahaan dan untuk cadangan premi. Cadangan premi harus secara bijak dikelola oleh perusahaan asuransi. Selain dikembalikan ke tertanggung dalam bentuk santunan, cadangan juga dapat digunakan apabila sewaktu-waktu terjadi hal yang tidak terduga seperti klaim di luar perkiraan [2].

Tidak sedikit perusahaan jasa asuransi jiwa yang mengalami kerugian karena tidak mampu membayar santunan kepada tertanggung. Hal ini dikarenakan ketika jumlah klain yang diajukan ileh tertanggung harus dibayar melebihi jumlah klaim yang diprediksi. Keadaan seperti ini dapat diantisipasi jika perusahaan jasa asuransi memiliki dana cadangan yang telah dipersiapkan dan diperhitungkan secara tepat [3].

Perhitungan cadangan premi tersebut dilakukan melalui metode perhitungan matematika aktuaria, yaitu dengan menggunakan metode retrospektif dan metode prospektif. Metode cadangan premi retrospektif merupakan metode cadangan yang menggunakan waktu yang lalu sebagai dasar perhitungan[4]. Metode cadangan premi prospketif merupakakan cadangan yang menggunakan waktu yang akan datang sebagai dasar perhitungannya. Dalam penelitian ini, metode yang digunakan adalah cadangan premi prospektif dan terdapat penelitian sebelumnya dengan judul Penentuan Cadangan Premi Pada Asuransi Jiwa Seumur Hidup Dengan Metode Zillmer oleh Lasta Dewi dkk pada tahun 2013 sebagai menambah pembahasan penelitian. Dengan demikian, penulis tertarik untuk meneliti tentang cadangan premi asuransi jiwa yang dituangkan dalam penelitian dengan judul "Penentuan Cadangan Premi Asuransi Jiwa Seumur Hidup Menggunakan Metode Zillmer”.

\section{Tinjauan Pustaka}

Definisi 1. Asuransi jiwa ialah janji perusahaan asuransi (pihak penanggung) kepada nasabahnya (tertanggung) apabila nasabah mengalami resiko kematian dalam hidupnya, perusahaan akan memberikan santunan (manfaat kematian) kepada ahli waris [1]. Asuransi jiwa memiliki macam-macam jenis produk yang masing-masing jenis produk memiliki manfaat yang berbedabeda. Berbagai jenis produk asuransi jiwa ini bertujuan untuk melayani macam-macam kebutuhan nasabah. Jenis asuransi jiwa merupakan asuransi yang objeknya orang atau asuransi yang berkaitan 


\section{Nur Iriana, Ika Purnamasari, and Yuki Novia Nasution}

dengan individu. Adapun resiko yang ditanggung dalam asuransi jiwa adalah kematian, kecelakan, sakit, dan umur tua [5].

Berbagai produk asuransi jiwa terdiri dari asuransi jiwa seumur hidup, asuransi jiwa berjangka, dan asuransi jiwa dwiguna. Asuransi jiwa seumur hidup adalah serangkain pembayaran (besarnya pembayaran berkala boleh berubah) yang dilakukan selama seseorang tertentu masih hidup. Pembayaran hanya dilakukan bila pemegang polis masih hidup [2].

Definisi 2. Metode Zillmer perhitungan cadangan yang melibatkan premi kotor dan premi bersih, premi kotor itu sendiri mengandung beberapa biaya yang digunakan oleh perusahaan asuransi. Metode Cadangan Zillmer ditemukan oleh Dr. August Zillmer (1831-1893). Metode Zillmer menggunakan cadangan premi prospektif sebagai dasar perhitungannya[2].

Definisi 3. Perhitungan cadangan premi prospektif didefinisikan sebagai selisih nilai santunan yang akan datang dengan nilai premi tunai yang akan datang [4]. Perhitungan cadangan premi prospektif untuk asuransi seumur hidup dapat ditulis

$$
{ }_{t} V=A_{x+t}-P . \ddot{a}_{x: \mathrm{t}}
$$

${ }_{t} V \quad=$ Cadangan premi prospektif tahun ke $\mathrm{t}$ untuk asuransi jiwa seumur hidup

$A_{x+t} \quad=$ Premi tunggal bersih untuk cadangan ke $\mathrm{t}$ tahun

$P . \ddot{a}_{x: \mathrm{t}}=$ Premi Bersih flat dan anuitas untuk cadangan ke $\mathrm{t}$ tahun

Dengan menggunakan Tabel Mortalitas Indonesia 1999 dan Tabel Mortalitas 2011 dapat dihitung nilai anuitas awal. Nilai anuitas awal adalah serangkaian pembayaran yang dilakukan pada awal tahun. Maka nilai anuitas awal dapat ditulis pada persamaan berikut[4] :

$$
\ddot{a}=\frac{N_{x}}{D_{x}}
$$

Premi tunggal bersih ialah premi yang dibayar pada saat kontrak disetujui dan hanya memperhatikan tingkat suku bunga dan tingkat mortalitas. Perhitungan premi tunggal bersih asuransi jiwa seumur hidup dapat ditulis

$$
A_{x}=\frac{M_{x}}{D_{x}}
$$

Setelah diperoleh nilai anuitas awal dan nilai premi tunggal bersih, maka dapat dihitung nilai premi bersih flat. Premi bersih flat adalah pembayaran yang dilakukan dengan masa kontrak sepanjang umur tertanggung dan premi dibayar berkala yaitu tahunan. Premi bersih flat dapat ditulis pada persamaan berikut :

$$
A_{x}=P \ddot{a}_{x}
$$

Misalkan premi bersih datar untuk asuransi seumur hidup dinyatakan dengan $\mathrm{P}$ dan premi kotor dinyatakan dengan $P^{\prime \prime}$ dan besarnya biaya yang dikeluarkan $\mathrm{k} \%$ dari premi kotor dan $\mathrm{b}$ rupiah dari perusahaan. Maka akan diperoleh hubungan sebagai berikut:

$$
P^{\prime}=P+k P^{\prime}, \text { k dalam } \%
$$

sehingga,

$$
P^{\prime}=\frac{1}{1-k} \cdot P
$$




\section{Nur Iriana, Ika Purnamasari, and Yuki Novia Nasution}

Misalkan biaya dari santunan adalah b, maka persamaan (5) menjadi:

$$
\begin{gathered}
P^{\prime \prime}=\frac{(P+b)}{1-k} \\
P^{\prime \prime}=P+k P^{\prime}+b
\end{gathered}
$$

Misalkan $\mathrm{f}$ menyatakan selisih antara biaya permulaan dengan biaya lanjutan per 1 rupiah santunan, dan misalkan seperti biasa, premi dibayar tahunan diperoleh

$$
P^{\prime \prime} \ddot{a}_{x}=\left(\mathrm{P}+k \mathrm{P}^{\prime}+b\right) \ddot{a}_{x}+f
$$

Dengan memindahkan nilai $\mathrm{f}$ ke ruas kiri maka nilai $\mathrm{f}$ menjadi :

$$
f=P^{\prime \prime} \ddot{a}_{x}-\left(P+a P^{\prime}+b\right) \ddot{a}_{x}
$$

Teorema 4. Pada konsepnya, cadangan premi pada tahun ke $x+t$ merupakan akumulasi dari satunan tahun ke $x+t$. Cadangan Zillmer menggunakan premi kotor maka santunan tersebut dikurangi dengan nilai tunai premi kotor yang akan datang ditambah dengan nilai tunai biaya. Dengan demikian, cadangan premi Zillmer $\left(V_{t}{ }^{z}\right)$ dapat ditulis menjadi:

$$
\begin{gathered}
{ }_{t} V^{z}=A_{x+t}-P^{\prime \prime} \ddot{a}_{x+t}+\left(k P^{\prime}+\mathrm{b}\right) \ddot{a}_{x+t} \\
=A_{x+t}-\left(P^{\prime \prime}-k P^{\prime}+\mathrm{b}\right) \ddot{a}_{x+t} \\
=A_{x+t}-\left[P^{\prime \prime}-k P^{\prime}+\mathrm{b}\right] \ddot{a}_{x+t}
\end{gathered}
$$

Dengan mensubtitusikan persamaan (1) ke persamaan (9) diperoleh :

$$
\begin{aligned}
{ }_{t} V^{z} & =A_{x+t}-\left(P+\frac{f}{\ddot{a}_{x}}\right) \ddot{a}_{x+t} \\
& =\left(A_{x+t}-P . \ddot{a}_{x+t}\right)-f . \frac{\ddot{a}_{x+t}}{\ddot{a}_{x}}
\end{aligned}
$$

Perhitungan cadangan metode Zillmer dalam penelitian ini akan menggunakan persamaan (10) dan cadangan prospektif sebagai dasar perhitungannya pada persamaan (1).

\section{Data}

Data penelitian ini adalah Data simulasi yang digunakan dalam penelitian ini adalah data umur nasabah dengan rentang 25-35 tahun, dengan jenis kelamin laki-laki dan perempuan. Dengan menggunakan santunan sebesar Rp. 500.000 .000 dan tingkat bunga sebesar 5.5\%. Perhitungan premi dibantu dengan Tabel Mortalitas Indonesia (TMI) 1999 dan TMI 2011.

\section{Kesimpulan}

Dari hasil analisis cadangan premi Zillmer berdasarkan jenis kelamin, dan usia diperoleh hasil cadangan premi Zillmer yang akan disajikan pada tabel 1 dan 2.

Tabel 1. Hasil Perhitungan Cadangan Premi Metode Zillmer $t=20$ untuk TMI 1999

\begin{tabular}{|c|c|c|}
\hline Usia & \multirow{2}{*}{ Santunan } & \multicolumn{2}{|c|}{ Cadangan Premi $t=20$} \\
\cline { 3 - 3 } Tertanggung & Laki-laki & Perempuan \\
\hline
\end{tabular}




\begin{tabular}{|l|l|l|l|}
\hline 25 & Rp 500.000.000 & Rp. 75.535.593 & Rp. 61.951.230 \\
\hline 26 & Rp 500.000.000 & Rp. 79.330.679 & Rp. 65.044.881 \\
\hline 27 & Rp 500.000.000 & Rp. 83.207.965 & Rp. 68.278.820 \\
\hline 28 & Rp 500.000.000 & Rp. 87.151.477 & Rp. 71.642.101 \\
\hline 29 & Rp 500.000.000 & Rp. 91.157.860 & Rp. 75.115.129 \\
\hline 30 & Rp 500.000.000 & Rp. 95.219.742 & Rp. 78.699.771 \\
\hline 31 & Rp 500.000.000 & Rp. 99.334.295 & Rp. 82.390.050 \\
\hline 32 & Rp 500.000.000 & Rp. 103.529.125 & Rp. 86.175.010 \\
\hline 33 & Rp 500.000.000 & Rp. 107.837.987 & Rp. 90.044.119 \\
\hline 34 & Rp 500.000.000 & Rp. 112.310.474 & Rp. 93.995.256 \\
\hline 35 & Rp 500.000.000 & Rp. 116.977.326 & Rp. 98.052.995 \\
\hline
\end{tabular}

Tabel 2 Hasil Perhitungan Cadangan Premi Metode Zillmer $t=20$ dengan TMI 2011

\begin{tabular}{|c|c|c|c|}
\hline \multirow{2}{*}{$\begin{array}{c}\text { Usia } \\
\text { Tertanggung }\end{array}$} & \multirow{2}{*}{ Santunan } & \multicolumn{2}{|c|}{ Cadangan Premi $t=20$} \\
\hline & & Laki-laki & Perempuan \\
\hline 25 & Rp 500.000.000 & Rp. 74.305.049 & Rp. 59.365.970 \\
\hline 26 & Rp 500.000.000 & Rp. 77.993.656 & Rp. 62.229.210 \\
\hline 27 & Rp 500.000.000 & Rp. 81.766.271 & Rp. 65.208 .102 \\
\hline 28 & Rp 500.000.000 & Rp. 85.594.752 & Rp. 68.276.901 \\
\hline 29 & Rp 500.000.000 & Rp. 89.467.155 & Rp. 71.444.344 \\
\hline 30 & Rp 500.000.000 & Rp. 93.396.711 & Rp. 74.706.850 \\
\hline 31 & Rp 500.000.000 & Rp.97.354.776 & Rp. 78.060.936 \\
\hline 32 & Rp 500.000.000 & Rp. 101.323.646 & Rp. 81.503.259 \\
\hline 33 & Rp 500.000.000 & Rp. 105.284.935 & Rp. 85.000.446 \\
\hline 34 & $\mathrm{Rp} 500.000 .000$ & Rp. 109.244.862 & Rp. 88.530 .569 \\
\hline 35 & Rp 500.000.000 & Rp. 113.201.019 & Rp. 92.074.973 \\
\hline
\end{tabular}

Hasil perhitungan pada tabel 4.1 dan 4.2 didapatkan dari persamaan (10) yang sebelumnya telah dihitung premi bersih flat pada persamaan (4), lalu dilanjutkan dengan menghitung premi kotor pada persamaan (6), dan menghitung selisih biaya yang dibayarkan menggunakan persaamaan (8). Kemudian, menghitung cadangan prospektif menggunakan persamaan (1) sebagai dasar perhitungan metode Zillmer.

Berdasarkan hasil perhitungan yang telah disajikan pada tabel 4.1 dan tabel 4.2 dapat dilihat bahwa terdapat perbedaan pada perhitungan cadangan premi menggunakan metode TMI 1999 dan TMI 2011. Perhitungan Cadangan Premi Zillmer menggunakan TMI 1999 membutuhkan cadangan premi yang lebih besar dibandingkan dengan cadangan premi Zillmer menggunakan TMI 2011. 


\section{Nur Iriana, Ika Purnamasari, and Yuki Novia Nasution}

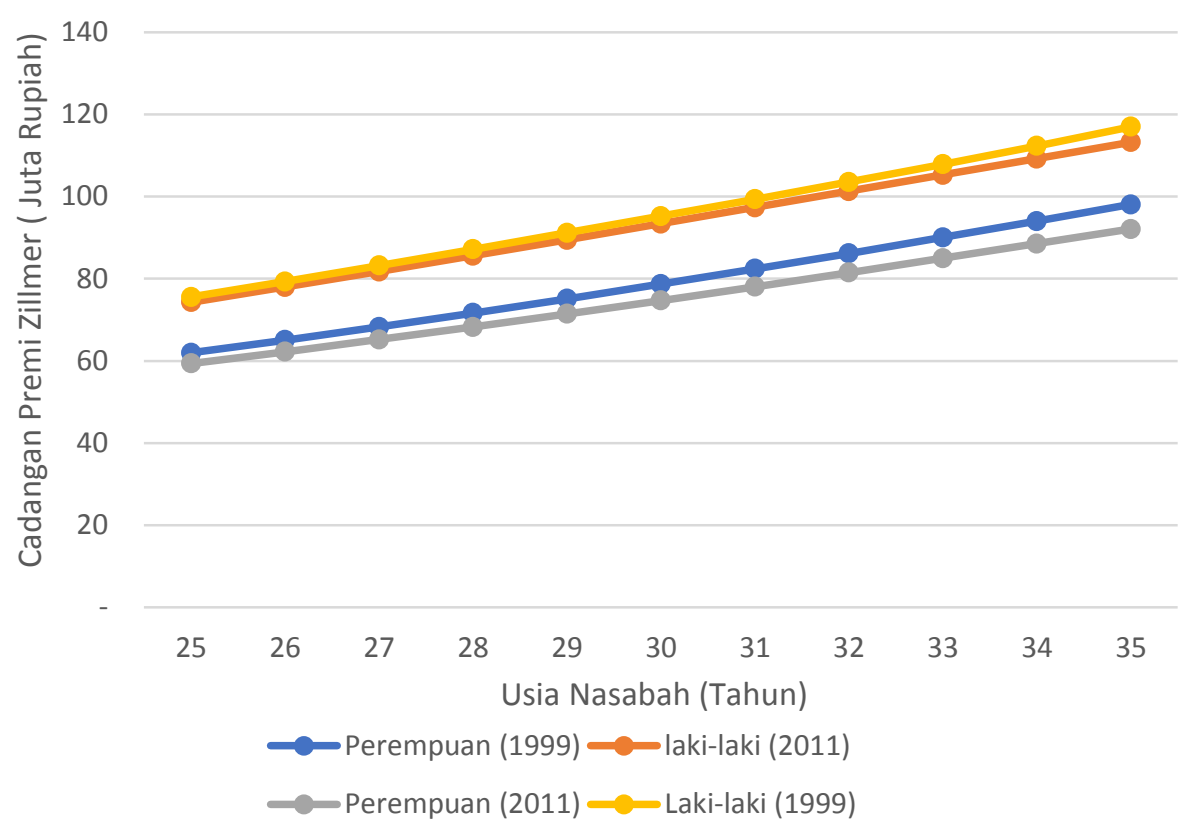

Gambar 4.1 Cadangan Premi Metode Zillmer Tahun ke-dua puluh dengan $k=3 \%$

Berdasarkan gambar 4.1, diperoleh bahwa cadangan premi Zillmer dengan menggunakan TMI 1999 lebih tinggi dibandingkan TMI 2011. Karena, tingkat risiko kematian yang dimiliki TMI 1999 lebih kecil daripada tingkat risiko kematian TMI 2011. Dengan demikian, Cadangan Premi yang diperlukan nasabah laki-laki karena tingkat risiko kematian yang dimiliki nasabah laki laki lebih tinggi dibandingkan dengan nasabah perempuan. Semakin bertambahnya usia nasabah cadangan premi yang diperlukan juga kian bertambah.

\section{DAFTAR PUSTAKA}

[1] Effendie, A.R. (2015). Matematika Aktuaria dengan Software R. Yogyakarta : Gadjah Mada University Press.

[2] Sembiring, R.K. (1986). Buku Materi Pokok Asuransi 1. Jakarta : Univesitas Terbuka.

[3] Destriani, Sathyahadewi, N., Mara, M.N. (2014). Penentuan Nilai Cadangan Prospektif pada Asuransi Jiwa Seumur Hidup Menggunakan Metode New Jersey. Buletin Ilmiah Mat.Stat dan Terapannya (BIMASTER). Vol.02 No.03 Hal 7-12.

[4] Futami, T. (1993). Matematika Asuransi Jiwa, Bagian I. Terj. Dari Seimei Hoken Sugaku, Jokan (92 Revision), oleh Herliyanto, G. Japan : Penerbit Incorporated Foundation Oriental Life Insurance Cultural Development Center.

[5] Darmawi, H. (2004). Manajemen Asuransi. Jakarta : PT Bumi Aksara. 


\section{Nur Iriana, Ika Purnamasari, and Yuki Novia Nasution}

[6] Nofridawati, N. (2012). Premi Asuransi Jiwa pada Akhir Tahun Kematian dan pada Saat Kematian Terjadi. Jurnal Matematika UNAND. Fakultas Matematika dan Ilmu Pengetahuan Alam Universitas Andalas Padang. Vol.1 No.2 Hal 79-84.

[7] Bowers, N. L., Geerber, H. U., Hickamn, J.C., Jones, D. A., \& Nesbitt, C. J. (1997). Actuarial Mathematics. Schaumhurg: Society Of Actuaries

[8] Karvof, A. (2010). Kaya Dengan Cepil. Jakarta : PT. Elex Media Komputindo.

[9] Ketut, S. (2004). Konsep dan Penerapan Asuransi Jiwa Unit-Link Proteksi Sekaligus Investasi. Jakarta : PPM.

[10] Ketut, S. (2007). Bancassurance = Bank + Asuransi. Jakarta : PPM.

[11] OJK. (2017). Buku Statistik Perasuransian 2017. Jakarta. Direktorat Statistika dan Informasi Industri Keuangan Non Bank.

[12] Prihantoro, M.W. (2000). Aneka Produk Asuransi dan Karakteristiknya. Yogyakarta: Kanisius.

[13] Siegel, J.S., Swanson D.A. (2004). The Methods and Materials of Demography. USA : Elsevier Inc.

[14] Undang-Undang Republik Indonesia Nomor 2. (1992). Usaha Perasuransian. Lembaran Negara Republik Indonesia Tahun 1992 Nomor 13. Jakarta 